ISSN 1981-416X

Licenciado sob uma Licença Creative Commons

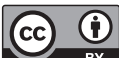

\title{
Tecnologias assistivas e inclusão escolar: o uso do software GRID 2 no atendimento educacional especializado a estudante com autismo em uma escola pública do Distrito Federal
}

\begin{abstract}
Assistive technology and school inclusion: the application of GRID 2 software in educational special treatment for a student with autism in a public school of Distrito Federal
\end{abstract}

\section{Flávia Ramos Cândido, Amaralina Miranda de Souza*}

Universidade de Brasília (UnB), Brasília, DF, Brasil

\section{Resumo}

Este estudo teve como principal objetivo analisar o uso do software GRID 2 e sua implicação nos processos de ensino-aprendizagem, comunicação e inclusão escolar de um estudante com autismo do Distrito Federal. A pesquisa fundamentou-se nos estudos de Bersch (2009), Galvão Filho \& Damasceno (2006) e Salomão (2013) e buscou compreender a organização do trabalho pedagógico no Atendimento Educacional Especializado (AEE) ofertado ao estudante com necessidades educacionais específicas (NEE). A metodologia utilizada foi a pesquisa-ação, que, conforme Barbier (2002), é apoiada em procedimentos cíclicos de reflexão e ação para favorecer o processo de mudança; o estudo de caso complementou o percurso metodológico. $\mathrm{O}$ estudo registrou maior articulação e colaboração entre os profissionais 
envolvidos no atendimento ao aluno, com evidência de melhora na sua comunicação e perspectiva de inclusão escolar por meio da tecnologia assistiva, e apontou para a necessidade de se investir na formação de professores de salas regulares e de sala de recursos multifuncionais para o uso dessas tecnologias no processo de ensino e aprendizagem.

Palavras-chave: Inclusão escolar. Software GRID 2. Tecnologias Assistivas. Autismo.

\begin{abstract}
This study aimed to analyze the use of GRID 2 software and its implication in the teachinglearning, communication and inclusion processes of a student with autism in the Federal District. The research was based on the studies of Bersch (2009), Galvão Filho \& Damasceno (2006) and Salomão (2013) and sought to understand the organization of pedagogical work in the Specialized Educational Assistance (AEE) offered to students with specific educational needs (SEN). The methodology used was the action research, which according to Barbier (2002), is supported in cyclical procedures of reflection and action to favor the process of change; the case study complemented the methodological approach. The study showed a greater articulation and collaboration among the professionals involved in student care, with evidence of improvement in their communication and perspective of school inclusion through assistive technology, and pointed to the need to invest in teacher training in regular and multifunctional resource rooms for the use of these technologies in the teaching and learning process.
\end{abstract}

Keywords: School inclusion. GRID Software 2. Assistive Technologies. Autism.

\title{
Introdução
}

Existe hoje uma realidade educacional na qual a inclusão é um imperativo ético preconizado na Política Nacional da Educação Especial na perspectiva da Educação Inclusiva (2008). Os estudantes com 
Necessidades Educacionais Específicas ${ }^{1}$ (NEE) possuem o direito de que os sistemas de ensino se movimentem e se organizem para desenvolverem, da melhor forma possível, ações que atendam suas demandas.

No contexto da educação inclusiva as salas de recursos se constituem em um apoio fundamental no processo de ensino e de aprendizagem do aluno com NEE. Para que este aluno possa efetivamente receber o apoio necessário que favoreça sua aprendizagem, além dos recursos, é indispensável que os profissionais possuam formação adequada e estejam em sintonia no atendimento às demandas educacionais dos estudantes.

Nesse sentido, o Governo do Distrito Federal (GDF) através da Coordenação de Educação Inclusiva (CEI) incluiu o software GRID 2 para atendimento a estudantes com necessidades educacionais específicas na fala. O GRID 2 foi destinado para algumas salas de recursos do DF e é uma ferramenta que se caracteriza como uma Tecnologia Assistiva (TA), ou seja, é uma tecnologia de apoio à aprendizagem direcionada para o público com disfunções motoras, sensoriais, com dificuldades ou impossibilidades de falar.

As questões a serem respondidas foram: O uso do software GRID 2 pode verdadeiramente facilitar a prática pedagógica do professor de Atendimento Educacional Especializado (AEE)? Será que os professores sabem utilizar essa tecnologia? Como os professores perceberam a inserção desse software em escolas públicas do DF e que implicações atribuem ao uso desta tecnologia no processo de ensino-aprendizagem e inclusão de estudantes com necessidades educacionais específicas? Este artigo apresenta os resultados de uma pesquisa de mestrado que teve como objetivo principal analisar o uso do software GRID 2 no AEE de uma escola da rede pública do DF e sua implicação no processo de ensino e de aprendizagem, de comunicação e de inclusão de um estudante com autismo.

1 "Necessidades educacionais especiais" e "necessidades educacionais específicas" são expressões que têm sido utilizadas por profissionais da Educação Especial em substituição a outras expressões atribuídas a esse alunado. 


\section{A pesquisa}

A metodologia utilizada nesta pesquisa, de abordagem qualitativa, parte do princípio de que para compreender o universo das relações humanas o pesquisador necessita estar envolvido na pesquisa. Só assim consegue entender os fatos e situações. O estudo de caso e a pesquisa-ação complementaram o percurso metodológico escolhido.

Importante destacar nossa intencionalidade em melhor compreender a realidade do estudante com vistas a favorecer mudanças em seu atendimento educacional. A este despeito, corroboramos com a definição de pesquisa-ação proposta por Barbier (2002), o qual acrescenta:

$\mathrm{O}$ pesquisador intervém de modo quase militante no processo, em função de uma mudança cujos fins ele define como estratégia. Mas a mudança visada não é imposta pelos pesquisadores. Resulta de uma atividade de pesquisa na qual os atores se debruçam sobre eles mesmos. Se o processo é induzido pelos pesquisadores, em função de modalidades que eles propõem, a pesquisa é efetuada pelos atores em situação e sobre a situação deles (BARBIER, 2002, p. 43).

O planejamento das ações da pesquisa prognosticou como primeira etapa compreender a processualidade da inserção do GRID 2 na rede pública de ensino do DF. Nessa etapa foi possível selecionar uma escola que conseguiu instalar o software e que o estava utilizando na sala de recursos. Também foi possível elencar os sujeitos da pesquisa. A partir daí, conseguimos elencar as estratégias pedagógicas utilizadas pela professora do AEE com o uso do GRID 2 na escola selecionada.

$\mathrm{Na}$ segunda etapa procuramos identificar o perfil do estudante e sujeito da pesquisa: nível de aprendizado e habilidades comunicativas. A partir dos objetivos definidos em conjunto pelas duas professoras que atendem o aluno e com a mãe do estudante, planejamos todas as ações desenvolvidas na sala de recursos com a utilização do software. Destacamos que antes da utilização do GRID 2 houve a necessidade de se confeccionar 
e utilizar recursos de baixa tecnologia ${ }^{2}$ como instrumentos de apoio no contexto escolar e domiciliar do estudante.

$\mathrm{Na}$ terceira etapa elaboramos e aplicamos o Plano de Atendimento Educacional Especializado e observamos o uso do software GRID 2 como recurso de apoio ao aluno no AEE.

O trabalho de pesquisa teve início em agosto de 2014 e totalizou três meses e dezoito dias de envolvimento com o objeto de estudo e contato com os sujeitos e com o ambiente escolar pesquisado. A pesquisa ocorreu em uma escola pública localizada em Ceilândia-DF. A escola atende 842 alunos de séries iniciais do ensino fundamental (primeiro ao quinto ano).

As duas professoras participantes da pesquisa são concursadas em cargo de professor da Secretaria de Educação do Distrito Federal (SEDF). Uma atua como professora de AEE em sala de recursos e a outra, como professora regente em turma de integração inversa ${ }^{3}$ do segundo ano do ensino fundamental. Importante destacar que a mãe do estudante também se configurou como sujeito de pesquisa. Consideramos importante informar que para preservar as identidades dos sujeitos da pesquisa serão utilizados nomes fictícios para identificá-los no texto. A professora da sala de recursos será identificada como "Taís"; a professora regente, "Júlia"; e o aluno, "Lucas".

Em agosto de 2014, no início da pesquisa, o aluno selecionado estava com oito anos e cinco meses de idade. Lucas passou por avaliações pela Equipe de Apoio à Aprendizagem da SEDF em 2012 que culminaram com a sua indicação para frequentar turma de integração inversa para o atendimento no contexto do Transtorno do Espectro Autista, para o ano de 2013. Lucas é um estudante que apresenta as características nucleares

2 Os recursos de baixa tecnologia mais comuns são os cartões e as pranchas de comunicação em forma de pastas, livros, fichários e pasta-arquivo. Geralmente têm baixo custo e permitem testar estratégias e técnicas para identificar as necessidades de comunicação do aluno.

3 Modalidade de atendimento previsto na estratégia de matrícula da SEDF. É uma classe comum criada para estudantes com deficiências e/ou TGD com modulação específica, em caráter transitório, por até, no máximo, três anos de escolarização, consecutivos ou não. 
que compõem o autismo infantil, como déficit na interação social, atraso na fala e comportamento repetitivo. $\mathrm{O}$ estudante não utiliza linguagem verbal e emite apenas alguns sons.

A organização da análise dos dados foi elencada de acordo com as etapas da técnica propostas por Bardin (2011) na qual as organiza em três fases: a) pré-análise; b) exploração do material; e c) tratamento dos resultados obtidos e interpretação.

Destacamos que em todo o procedimento de análise dos dados de pesquisa houve a preocupação em buscar relacionar e referenciar o material selecionado com a fundamentação teórica, tendo como luz os objetivos de pesquisa.

\section{O software GRID 2}

O estudo exploratório inicial possibilitou compreender que o GRID 2 é uma solução informática destinada especificamente a pessoas que apresentam deficiência neuromotora ${ }^{4}$. Este software foi concebido para o usuário poder expressar-se e comunicar-se de forma autônoma, utilizando o computador e os programas nele contidos, navegando na internet e ainda controlando totalmente o seu ambiente físico: abertura e fechamento de janelas, acesso ao telefone, TV, equipamento de áudio e vídeo, etc.

Criado na Inglaterra nos 1990, desenvolvido pela Sensory Software/LD, o GRID 2 permite variadas formas de comunicação, ou seja, o computador torna-se um comunicador por meio de fala sintetizada e outras formas de comunicar ${ }^{5}$. O GRID 2 é uma ferramenta de Comunicação

${ }^{4} \mathrm{O}$ termo neuromotora reporta-se às deficiências ocasionadas por lesões nos centros e vias nervosas que comandam os músculos. Podem ser causadas por infecções ou por lesões ocorridas em qualquer fase da vida da pessoa ou por uma degeneração neuromuscular cujas manifestações exteriores consistem em fraqueza muscular, paralisia ou falta de coordenação (BRASIL, 2006).

5 Por meio de e-mails ou Short Message Service (SMS), por exemplo. 
Aumentativa Alternativa ${ }^{6}$ que possui aproximadamente vinte mil símbolos e destina-se a pessoas que utilizam ou não mouse e teclado.

Figura 1 - Tela inicial do software GRID 2

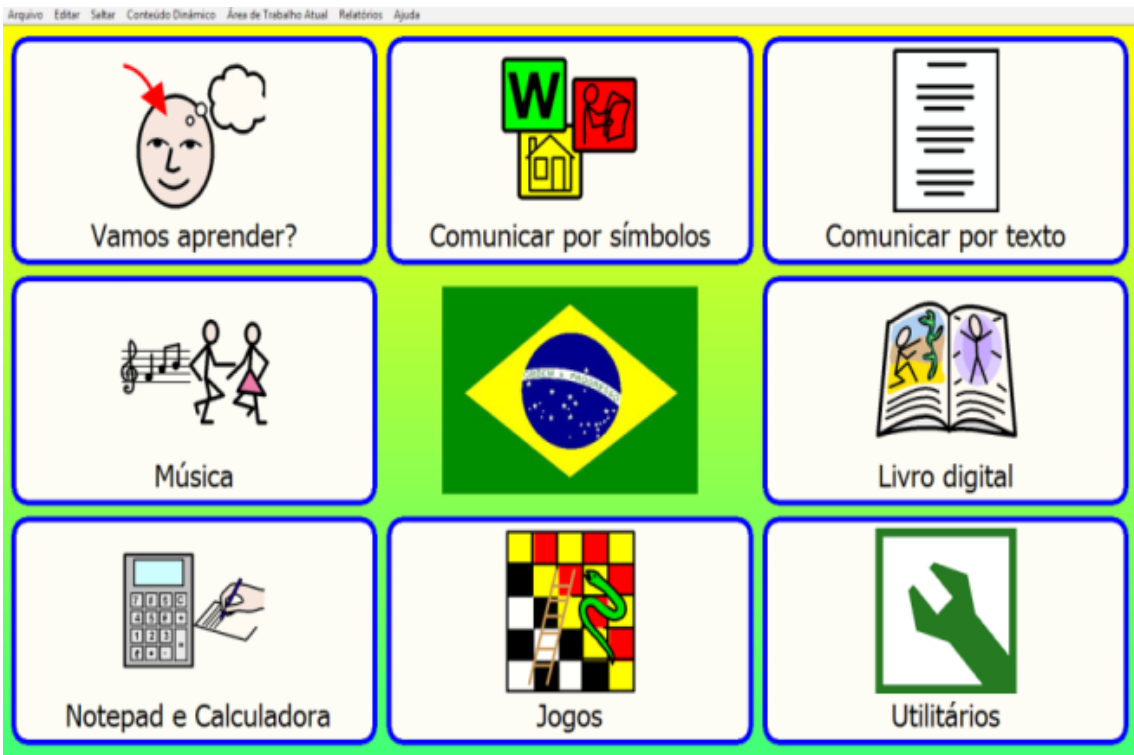

Fonte: As autoras (2014).

No GRID 2 os teclados são quadros ou páginas com células. A maioria das células pode incluir funções de fala, escrita ou de ligações a outros teclados. De acordo com o sítio TECASSISTIVA (2015), o software foi desenvolvido para ser universalmente acessível. Permite que estudantes NEE possam acessar o computador, através de diferentes tipos de

6 A área da tecnologia assistiva que se destina especificamente à ampliação de habilidades de comunicação é denominada de Comunicação Alternativa (CA). A comunicação alternativa destina-se a pessoas sem fala ou sem escrita funcional ou em defasagem entre sua necessidade comunicativa e sua habilidade de falar e/ou escrever (TECASSISTIVA, 2015). 
interfaces de acesso, tais como mouse, tela tátil, mouse marble, joysticks ou até mesmo interfaces de acesso pelo olhar.

\section{A oferta das licenças para o uso do GRID 2 no Distrito Federal}

Na primeira etapa da pesquisa procuramos compreender como o software GRID 2 adentrou as escolas do sistema público de ensino do Distrito Federal e qual seria a realidade dessas instituições de ensino para o cumprimento da proposta de instalação e uso da ferramenta.

Nessa etapa nos utilizamos de revisão bibliográfica e pesquisa documental para buscar subsídios teóricos e práticos para a fundamentação do estudo. Utilizamos como estratégia de pesquisa entrevistas semiestruturadas com agentes públicos que propuseram a implantação do software no DF.

Identificamos que o software foi uma tecnologia doada para a SEDF. No total, 70 (setenta) escolas que possuíam estudantes com autismo ou com necessidades específicas na comunicação receberam gratuitamente a licença de uso dessa tecnologia.

Após as entrevistas, ratificou-se a necessidade de fazer contato com as escolas que receberam o GRID 2 para a coleta de mais informações por meio da aplicação de questionários online aos professores, com vistas a conhecer esse processo de implantação a partir dos olhares destes profissionais. Como houve pouca adesão ao questionário online, decidimos visitar as escolas que receberam as licenças de uso do software para realizar o questionário in loco. No total, foram 49 escolas visitadas. Deste total, apenas duas escolas no DF conseguiram instalar e estavam utilizando o software.

Foi possível constatar que múltiplos fatores, que se inter-relacionam, determinaram as características da processualidade da introdução do software GRID 2 no contexto educativo no DF. De maneira geral, percebemos que as complexidades encontradas na fase de inserção desta tecnologia nas escolas podem ser caracterizadas como dificuldades de ordem estrutural e político-pedagógica: 
- Estrutural porque a estrutura física das escolas não foi projetada para receber a referida tecnologia, o que se revela na incompatibilidade nos sistemas operacionais dos computadores para a instalação do software GRID 2 e nos problemas relativos à qualidade ou ausência da internet nas instituições de ensino.

- Político-pedagógica porque os educadores não foram considerados no processo de inserção desta tecnologia tendo em vista que não participaram da seleção do software; não participaram do processo de definição das escolas que deveriam receber a ferramenta; não houve formação dos professores para uso desta tecnologia; não foi observada uma articulação entre a inserção da tecnologia com os projetos político-pedagógicos das escolas.

As visitas às instituições escolares para a aplicação dos questionários, outra estratégia de pesquisa utilizada, revelaram-se fundamentais uma vez que viabilizaram o conhecimento de uma escola cuja professora do AEE havia instalado e estava utilizando o software GRID 2, que depois se configuraram no local e sujeitos de nosso estudo.

As informações obtidas com o questionário aplicado à professora supracitada possibilitaram o conhecimento de que esta profissional instalou o software em sua própria residência, já que não havia internet na sala de recursos em que atua. A professora utilizava o software com seis estudantes NEE ( 4 com TGD, 1 com Deficiência Física e 1 com Deficiência Intelectual), geralmente uma vez por semana. Indicou também que a docente foi ajudada por um professor de Classe Especial que estava elaborando atividades usando o software. Por fim, indicou que a professora gostaria de "um suporte" ou curso para aprender a lidar com a tecnologia.

Esta professora manifestou interesse em colaborar com a pesquisa científica e solicitou ajuda no sentido de aplicar o software na sala de recursos, sinalizando a necessidade de apoio da pesquisadora para um trabalho conjunto de aplicação da ferramenta. 


\section{A proposta de uma nova prática pedagógica}

Constatamos, com a observação inicial, que o uso do GRID 2 pela professora no AEE ocorria ainda de forma tímida, sem o desenvolvimento de atividades planejadas e elaboradas, a partir de recursos já prontos, oferecidos pela ferramenta. Estes fatores nos incitaram a responder o convite da professora para adentrar o espaço escolar da sala de recursos, no intuito de colaborar na organização das estratégias pedagógicas necessárias para se utilizar o sistema de comunicação aumentativa alternativa proposto pelo GRID 2.

Verificamos alguns obstáculos na elaboração do planejamento pedagógico do Atendimento Educacional Especializado. Ratificamos nossa verificação nos estudos de Salomão (2013), que apontam que existem dificuldades no trabalho realizado na sala de recursos quanto à sistematização do plano de AEE, bem como a necessidade de implementação do uso de tecnologias no atendimento especializado.

A partir desse referencial e das demandas reveladas na escola pesquisada, optamos por buscar um modo mais efetivo de sistematizar o uso do GRID 2 na sala de recursos, por meio da elaboração de um plano de atendimento na sala de recursos com o uso de sistemas de comunicação aumentativa alternativa.

Para esta etapa, foi importante adotar a estratégia de observação do estudante em atividades na sala de aula comum e na sala de recursos, com vistas a conhecer suas respostas às estratégias de ensino utilizadas pelas professoras para seu atendimento, bem como pelo interesse de identificar os detalhes em sua aprendizagem e suas habilidades comunicativas.

A estratégia seguinte foi a proposta de efetivar um plano de ações elaborado em conjunto com as professoras e a ser desenvolvido no AEE. Tal estratégia se mostrou bastante positiva, no entanto, foi necessário integrar outros instrumentos de coleta de informações para dar conta de responder os objetivos da pesquisa.

Dessa forma, para conhecer seu perfil e percurso pedagógico, analisamos alguns documentos de Lucas (relatórios psicopedagógicos, 
relatórios escritos pelas professoras da classe comum e da sala de recursos, e laudo médico). Realizamos também entrevistas semiestruturadas iniciais com a professora da sala de recursos e com a professora regente, no intuito de conhecer a forma de atendimento oferecido e o perfil do aluno a partir das considerações das professoras, bem como as tecnologias assistivas por elas utilizadas.

De maneira geral, pudemos reconhecer naquele momento que Lucas realmente possuía as características nucleares que compõem o chamado Transtorno do Espectro Autista (TEA). Na análise de seus documentos não foi identificado histórico de uso e/ou experiências de sistemas de comunicação alternativa em sua vida escolar. Verificamos também que a professora Júlia desconhecia sistemas de CAA.

No contexto escolar, Lucas era tratado pelos professores, servidores e demais estudantes com carinho e respeito, mas permanecia a maior parte do tempo alheio às atividades propostas pela professora da sala de aula. Lucas costumava correr e brincar sozinho durante o recreio; evidenciou apreciar atividades de mesa, com recorte, colagem e pintura, sendo estas as principais atividades que realizava, sendo sempre auxiliado pela professora ou por um colega da turma. Registramos uma dificuldade de interação com Lucas já que o estudante não tinha a fala articulada.

No intuito de facilitar a comunicação do estudante, a professora Taís fixou, sem sucesso, folhas A4 na parede da sala de aula impressas com imagens de materiais escolares, do armário, da turma, da professora e do vaso sanitário, a fim de que Lucas apontasse o que desejava ou que queria comunicar. Reconheceu-se o esforço das professoras em estabelecer uma maneira efetiva de comunicação, na tentativa de oportunizar ao estudante uma forma para que ele fosse mais bem compreendido.

Percebemos que o planejamento de ações a serem desenvolvidas com Lucas deveria ser realizado de forma colaborativa entre as professoras e que as observações da pesquisadora seriam consideradas para a retroalimentação da prática pedagógica no âmbito das atividades realizadas pelas docentes. 
Dessa forma, foram realizados três encontros semanais com as professoras. Num deles contamos com a presença da mãe do aluno. De maneira geral, foram acordadas estratégias de acompanhamento pedagógico pelas duas professoras no sentido de buscar a melhoria da qualidade do atendimento ofertado, com vistas a dar respostas às diversas necessidades educacionais demandadas pelo estudante na sala de aula, na sala de recursos e também na sua residência.

Consideramos importante que as professoras pudessem discutir propostas para a elaboração de atividades que favorecessem maior nível de autonomia do estudante em relação à realização das atividades escolares; incentivar a socialização com os colegas de turma por iniciativa do estudante; auxiliar o processo de decodificação de letras (vogais e consoantes) a partir do nome próprio e de seus colegas em textos escritos; auxiliar o estudante a relacionar imagens com objetos, entre outras possibilidades.

Houve, então, a necessidade de se recorrer em conjunto com as professoras à literatura científica, com vistas a conhecer investigações feitas no campo dos modelos de intervenção e outras referências usados no contexto educativo de estudantes com autismo, em especial sobre o sistema PECS ${ }^{7}$.

Dessa forma, a partir da leitura ${ }^{8}$ sobre recursos e atividades de CAA seguida dos comentários das professoras e da mãe, e para anteceder o uso do software GRID 2 no Atendimento Educacional Especializado, foram estabelecidas as seguintes estratégias com vistas a uma nova prática para com o estudante, a saber:

7 O PECS, também conhecido por Sistema de Comunicação por Troca de Imagens (Picture Exchange Communication System), é um sistema que permite desenvolver a comunicação interpessoal, principalmente em pessoas com dificuldades severas de comunicação (BERSCH, 2009).

8 Foi realizada a leitura breve de uma síntese de textos, organizada pela pesquisadora, contendo sugestões sobre recursos e sistemas de comunicação alternativa para atender às demandas mais imediatas das professoras. Esta síntese foi entregue à professora regente no intuito de colaborar com sua prática pedagógica. 


\section{a) Avaliação pedagógica inicial do estudante}

Recorremos a uma observação pontual de Lucas. Corroboramos com Galvão Filho e Damasceno (2006) quanto à necessidade de um conhecimento detalhado sobre o aluno. De acordo com os autores:

[...] as decisões sobre as Tecnologias Assistivas que serão utilizadas com os alunos têm que partir de um estudo pormenorizado e individual, com cada um. Deve começar com uma análise detalhada e escuta profunda de suas necessidades, para, a partir daí, ir optando pelos recursos que melhor respondam a essas necessidades (GALVÃO FILHO; DAMASCENO, 2006, p. 32).

Nesse sentido, os relatos da mãe promoveram o conhecimento do estudante em seu contexto familiar. Os dados do diário de campo contribuíram para desvelar seu comportamento nos diversos contextos da escola. A leitura cuidadosa de seus documentos (Relatórios Pedagógicos e Adequação Curricular), o preenchimento da Ficha Cumulativa Adaptada ${ }^{9}$, da Ficha de avaliação psicopedagógica ${ }^{10}$ do estudante com Transtorno do Espectro do Autismo e do questionário de repertório comunicativo ${ }^{11}$ respondido pela mãe e pela professora do estudante sintetizam os instrumentos utilizados para esta avaliação inicial.

${ }^{9}$ A Ficha Cumulativa permitiu que a professora regente identificasse o desenvolvimento do estudante nos aspectos relativos à interação social, desenvolvimento psicomotor, desenvolvimento da linguagem, desenvolvimento das funções intelectuais e organização do pensamento, interrelacionando este instrumento com o relatório pedagógico do estudante.

${ }^{10}$ A ficha de avaliação psicopedagógica do estudante com autismo, preenchida pela pesquisadora e pela professora da sala de recursos, ofereceu uma visão geral sobre o processo de ensino e de aprendizagem, inter-relacionando estes achados com a Adequação Curricular do estudante.

${ }^{11}$ O questionário de repertório comunicativo (adaptado de WALTER, 2000), respondido pela mãe e pela professora regente, contribuiu para conhecer as principais formas de comunicação utilizadas por Lucas e para elucidar as dificuldades da professora e da família em compreender seus desejos e sentimentos. 
Os instrumentos revelaram que Lucas apresentava muitos comportamentos favoráveis ao desenvolvimento, no entanto, possuía latentes necessidades comunicacionais. Arriscamos inferir que o fato de o estudante nunca ter utilizado sistemas de comunicação aumentativa alternativa em seu contexto domiciliar ou educacional pode ter minimizado as suas possibilidades de comunicação. A partir destas constatações, prosseguimos para outra fase do estudo.

\section{b) Confecção de recursos de baixa tecnologia}

O planejamento para a confecção e uso de recursos de baixa tecnologia caracterizou-se como uma estratégia pedagógica para anteceder o atendimento na sala de recursos com o uso do software GRID 2, uma vez que ficou constatado que as professoras, o estudante e sua mãe nunca haviam utilizado sistemas de comunicação alternativa, ratificando a necessidade de ampliar a forma de comunicação para que Lucas pudesse ser mais bem compreendido, sobretudo, para significar a utilização do software, que requer esses elementos como base para a potencializar sua aplicação. Assim, algumas ações foram organizadas e realizadas da seguinte forma:

Tabela 1 - Ações para confecção de recursos de baixa tecnologia

\begin{tabular}{|c|c|c|c|}
\hline AÇÃO & PARTICIPANTES & FREQUÊNCIA & OBJETIVO \\
\hline $\begin{array}{l}\text { Seleção de } \\
\text { imagens para } \\
\text { confecção dos } \\
\text { recursos de baixa } \\
\text { tecnologia }\end{array}$ & $\begin{array}{l}\text { Professora do AEE } \\
\text { Estudante } \\
\text { Turma de Integração } \\
\text { Inversa } \\
\text { Pesquisadora } \\
\text { Professora regente } \\
\text { Família do estudante }\end{array}$ & Duas semanas & $\begin{array}{l}\text { Captação de imagens para } \\
\text { confecção de recursos de baixa } \\
\text { tecnologia }\end{array}$ \\
\hline $\begin{array}{l}\text { Confecção dos } \\
\text { recursos de baixa } \\
\text { tecnologia }\end{array}$ & Pesquisadora & Duas semanas & $\begin{array}{l}\text { Confecção de jogo, confecção } \\
\text { de atividade de loto-leitura } \\
\text { e confecção de cartões de } \\
\text { comunicação (quadro de rotina) } \\
\text { para uso no AEE, na sala de aula } \\
\text { e em casa }\end{array}$ \\
\hline
\end{tabular}




\begin{tabular}{|c|c|c|c|}
\hline $\begin{array}{l}\text { Atendimento do } \\
\text { estudante em } \\
\text { sala de aula }\end{array}$ & $\begin{array}{l}\text { Professora regente } \\
\text { Estudante }\end{array}$ & $\begin{array}{l}\text { Todos os dias, no } \\
\text { estabelecimento } \\
\text { da rotina escolar } \\
\text { e na execução } \\
\text { de atividades } \\
\text { a serem } \\
\text { desenvolvidas } \\
\text { pelo estudante }\end{array}$ & $\begin{array}{l}\text { Utilizar os recursos de baixa } \\
\text { tecnologia, o jogo da memória e } \\
\text { a atividade de loto-leitura como } \\
\text { recursos de apoio }\end{array}$ \\
\hline $\begin{array}{l}\text { Atendimento do } \\
\text { estudante em } \\
\text { casa }\end{array}$ & $\begin{array}{l}\text { Família do estudante } \\
\text { Estudante }\end{array}$ & $\begin{array}{l}\text { Todos os dias, } \\
\text { nos momentos } \\
\text { de rotina e } \\
\text { atividades de } \\
\text { vida diária. }\end{array}$ & $\begin{array}{l}\text { Utilizar em casa o quadro de } \\
\text { rotina como recurso de apoio à } \\
\text { comunicação }\end{array}$ \\
\hline $\begin{array}{l}\text { Registro do } \\
\text { atendimento } \\
\text { realizado na sala } \\
\text { de aula }\end{array}$ & $\begin{array}{l}\text { Pesquisadora, } \\
\text { Professora da sala de } \\
\text { recursos e professora } \\
\text { regente. }\end{array}$ & $\begin{array}{l}\text { Quinzenalmente } \\
\text { (período de } \\
15 \text { minutos) } \\
\text { durante o } \\
\text { período de } \\
\text { coordenação } \\
\text { (planejamento) } \\
\text { da professora } \\
\text { regente }\end{array}$ & $\begin{array}{l}\text { Discutir o processo de } \\
\text { desenvolvimento do estudante, } \\
\text { indicar os avanços, trocar } \\
\text { experiências e redirecionar a ação }\end{array}$ \\
\hline $\begin{array}{l}\text { Registro do } \\
\text { atendimento } \\
\text { realizado em } \\
\text { casa }\end{array}$ & $\begin{array}{l}\text { Pesquisadora e mãe } \\
\text { do estudante }\end{array}$ & $\begin{array}{l}\text { Quinzenalmente } \\
\text { (período de } \\
10 \text { minutos) } \\
\text { na residência } \\
\text { do estudante } \\
\text { ou no local de } \\
\text { trabalho do pai } \\
\text { do estudante }\end{array}$ & $\begin{array}{l}\text { Discutir o processo de } \\
\text { desenvolvimento do estudante, } \\
\text { indicar os avanços, trocar } \\
\text { experiências e redirecionar a ação }\end{array}$ \\
\hline $\begin{array}{l}\text { Avaliação do } \\
\text { processo de uso } \\
\text { dos recursos de } \\
\text { baixa tecnologia }\end{array}$ & $\begin{array}{l}\text { Professora da sala de } \\
\text { recursos } \\
\text { Professora regente } \\
\text { Estudante } \\
\text { Pesquisadora } \\
\text { Mãe do estudante }\end{array}$ & Um encontro & $\begin{array}{l}\text { Avaliar as contribuições e } \\
\text { pertinência das ações em todas } \\
\text { as suas perspectivas (intervenção } \\
\text { pedagógica, uso dos recursos } \\
\text { de baixa tecnologia, orientações } \\
\text { à família, prosseguimento do } \\
\text { trabalho desenvolvido). Esboçar } \\
\text { o trabalho a ser desenvolvido } \\
\text { com o software GRID } 2\end{array}$ \\
\hline
\end{tabular}

Fonte: dados da pesquisa.

Levamos em consideração que, apesar dos grandes avanços e descobertas feitas sobre o Transtorno do Espectro do Autismo, ainda há muito por investigar e descobrir, já que o quadro apresentado por essas crianças é intrigante e desafia o conhecimento sobre o ser humano e sua 
natureza em geral. Daí a necessidade de se vislumbrar e explorar esta temática de uma forma multifacetada, e não com uma postura unilateral e isolada, de maneira a considerar o estudante com autismo como sujeito de possibilidades.

Correia (2014) destaca ainda que, antes de se iniciar um sistema de CAA é necessário fazer uma procura para averiguar quais as preferências da criança. Estas preferências podem estar relacionadas com a alimentação ou com outros tipos de itens, e são chamados de reforços. O uso desses reforços é bastante valorizado pela criança, eles podem ser apresentados através de símbolos ou imagens (fotografias) organizados para serem utilizados frequentemente.

A necessidade de utilizar os reforços possibilitou a confecção de um quadro de preferências, que foi preenchido pela mãe de Lucas, e serviu como aporte para a confecção dos recursos de baixa tecnologia e para a futura seleção de figuras para a confecção de pranchas de comunicação no software GRID 2.

A partir do quadro de preferências e da visualização de vídeos sobre o sistema PECS iniciamos o processo de captação de imagens de Lucas nos vários momentos e espaços da escola e na sua rotina doméstica, com vistas à construção de cartões de comunicação. Uma câmera fotográfica foi entregue à professora Júlia e posteriormente à mãe de Lucas, sendo a elas solicitado que fotografassem o estudante nos momentos da rotina diária de sala de aula e na rotina familiar. A professora Taís também capturou imagens nos momentos vivenciados com o estudante na sala de recursos.

Para a realização deste estudo, não tivemos a pretensão de adotar o sistema PECS de forma rígida, seguindo estrategicamente as etapas que este sistema requer. Ao contrário, a inserção dos recursos de baixa tecnologia serviu de pontapé importante para a prática dos sujeitos envolvidos quanto ao conhecimento e possibilidades com sistemas de comunicação alternativa na rotina de Lucas.

Assim, aplicamos recursos de baixa tecnologia, contendo símbolos e imagens, para facilitar a comunicação de Lucas. Para Zaporoszenko 
e Alencar (2008), os símbolos são as formas de representação de objetos, pessoas, ações, relações e conceitos e são utilizados para expor pensamentos e conceitos concretos ou abstratos. Podem ser acústicos, gráficos, gestuais ou táteis, ou constituir-se de expressões faciais ou visuais e movimentos corporais. Nesse sentido, segundo as autoras, "na comunicação assistida, o indivíduo necessita de materiais como objetos, palavras escritas, fotografias e outros recursos para se comunicar" (ZAPOROSZENKO \& ALENCAR, 2008. p. 9).

A introdução destas atividades favoreceu o trabalho com a linguagem oral, havendo a valorização da intenção comunicativa pela observação da expressão de desejos, necessidades, ideias e fatos, em conjunto com gestos, expressões faciais e outras produções (orais ou não) que pudessem veicular sentidos e promover competências comunicativas do estudante.

Foram, então, confeccionados um jogo de relação objeto/figura, um caderno de comunicação (com atividades de loto-leitura), um quadro para se trabalhar a rotina escolar e um quadro para se trabalhar a rotina domiciliar de Lucas. Estes materiais foram entregues à professora Júlia e à família de Lucas no final do mês de setembro de 2014. Após a explicitação dos objetivos e sugestões de trabalho com os recursos ficou acordado que estes deveriam ser utilizados durante o quarto bimestre, na rotina diária da escola e na residência de Lucas.

Após um mês e meio de trabalho com o uso dos recursos de baixa tecnologia, constatamos que o trabalho em colaboração com objetivos comuns facilitou o acesso do estudante a novas experiências de aprendizagem.

Os relatos da professora regente sobre o uso dos recursos de baixa tecnologia mostraram que eles ajudaram Lucas a perceber que através da comunicação, principalmente com a ação de apontar para as fichas que continham fotos, ele poderia conseguir mais rapidamente o que deseja, estimulando-o assim a comunicar-se e, consequentemente, ajudando a minimizar problemas na interpretação e/ou entendimento de seus reais desejos, ou ainda minimizando problemas em seu comportamento. 


\section{O plano de ações no Atendimento Educacional Especializado}

A partir da identificação dos conhecimentos pedagógicos e das características pessoais e comunicacionais de Lucas foi possível selecionar, em conjunto com as professoras, as áreas do currículo a serem trabalhadas com as pranchas de comunicação do software GRID 2.

Com isso, delineamos um Plano de Atendimento Educacional Especializado com o uso do software GRID 2 (PAESG2). O trabalho realizado na sala de recursos foi direcionado a partir do PAESG2 e traçados os objetivos a serem alcançados durante o quarto bimestre do ano letivo.

É importante destacarmos que a professora do AEE, assim como os demais profissionais que tiveram a ferramenta contemplada em suas escolas, não recebeu formação específica para utilizá-la. Para esta pesquisa, foram então considerados os níveis de conhecimento da professora de AEE em relação à ferramenta para o planejamento, confecção e aplicação das pranchas de comunicação.

Nesse sentido, os atendimentos foram planejados em sessões. Ao todo, foram realizadas dez sessões com duração de até cinquenta minutos. Ao finalizar o atendimento, a professora se apoiava nas observações e reflexões sobre o atendimento que havia acabado de realizar com Lucas para então planejar os atendimentos e a confecção da prancha e demais atividades seguintes.

As pranchas utilizadas se caracterizaram pela necessidade em se realizar trocas dialógicas com o estudante a partir de atividades cotidianas como, por exemplo, alimentação, lazer e autocuidado. Desse modo, as pranchas foram confeccionadas de acordo com as seguintes especificações: 
Tabela 2 - Especificações das pranchas confeccionadas no GRID 2

\begin{tabular}{|c|c|c|}
\hline TEMA & OBJETIVOS PRINCIPAIS & ESPECIFICAÇÕES \\
\hline Minha Família & $\begin{array}{l}\text { Identificar a família } \\
\text { do estudante, o } \\
\text { nome dos familiares, } \\
\text { características, } \\
\text { preferências, o } \\
\text { que fazem, em que } \\
\text { trabalham, etc. Explorar } \\
\text { preferências do } \\
\text { estudante e oportunizar } \\
\text { trocas dialógicas tendo } \\
\text { como referência seu } \\
\text { cotidiano familiar. }\end{array}$ & \multirow{5}{*}{$\begin{array}{l}\text { Pranchas em formato horizontal, em cores } \\
\text { suaves. } \\
\text { Escrita da frase de abertura em caixa-alta. } \\
\text { Incluem imagens reais referentes ao } \\
\text { estudante em seu contexto domiciliar e } \\
\text { escolar, bem como imagens (desenhos) } \\
\text { retirados da internet. } \\
\text { Possuem varredura manual. } \\
\text { A varredura pode ser feita através do mouse. } \\
\text { A construção e edição das pranchas de } \\
\text { comunicação só podem ser realizadas pelo } \\
\text { acesso direto. } \\
\text { Partes principais: } \\
\text { - área da frase, } \\
\text { - grupo dos símbolos, } \\
\text { - botões funcionais. } \\
\text { Recursos especiais: } \\
\text { - autoclique, } \\
\text { - varredura, } \\
\text { - gravação de voz, } \\
\text { - adição de mensagens (reforço positivo). }\end{array}$} \\
\hline Minha Casa & $\begin{array}{l}\text { Estabelecer trocas } \\
\text { dialógicas a partir da } \\
\text { identificação da casa } \\
\text { do estudante, trabalhar } \\
\text { os nomes, funções } \\
\text { e características dos } \\
\text { diversos espaços da } \\
\text { residência. Explorar locais } \\
\text { e objetos preferidos pelo } \\
\text { estudante tendo como } \\
\text { referência seu contexto } \\
\text { domiciliar. }\end{array}$ & \\
\hline Minha Escola & $\begin{array}{l}\text { Identificar a escola do } \\
\text { estudante, trabalhar os } \\
\text { nomes, características e } \\
\text { funções dos ambientes } \\
\text { do espaço escolar. } \\
\text { Explorar locais e } \\
\text { objetos preferidos pelo } \\
\text { estudante no contexto } \\
\text { escolar. Trabalhar a } \\
\text { rotina escolar. }\end{array}$ & \\
\hline Higiene Pessoal & $\begin{array}{l}\text { Estabelecer trocas } \\
\text { dialógicas para trabalhar } \\
\text { a rotina e a higiene } \\
\text { pessoal, esclarecendo } \\
\text { sua importância. }\end{array}$ & \\
\hline Alimentos & $\begin{array}{l}\text { Estabelecer trocas } \\
\text { dialógicas para } \\
\text { trabalhar a imaginação } \\
\text { e a expressividade a } \\
\text { partir das preferências } \\
\text { alimentares do estudante. }\end{array}$ & \\
\hline
\end{tabular}

Fonte: dados da pesquisa. 
De forma não linear, foram descritos os planejamentos e interlocuções ocorridos antes, durante e após as dez sessões destinadas para uso do GRID 2. Outra intenção/sugestão discutida a partir das sessões foi a de imprimir e plastificar as pranchas utilizadas para uso em sala de aula junto com o caderno de comunicação.

Confeccionamos também um arquivo digital contendo os registros do atendimento do estudante com o uso do software GRID 2. A seguir é apresentado um exemplo de registro descritivo e reflexivo das sessões realizadas no AEE.

Tabela 3 - Registro da terceira sessão com o uso do GRID 2

\begin{tabular}{|c|c|c|c|}
\hline $\begin{array}{l}\text { 3a Sessão } \\
\text { Prancha } \\
\text { MINHA CASA } \\
\text { Data: } \\
\text { 11/11/14 } \\
\text { Duração do } \\
\text { atendimento: } \\
18 \text { minutos }\end{array}$ & $\begin{array}{l}\text { Recursos } \\
\text { Prancha contendo imagens } \\
\text { reais da casa do estudante } \\
\text { (cômodos) e seus respectivos } \\
\text { nomes. } \\
\text { Atividade complementar: } \\
\text { confecção de "casinha" através } \\
\text { de colagem com figuras } \\
\text { geométricas; desenho e } \\
\text { pintura. }\end{array}$ & $\begin{array}{l}\text { Objetivos } \\
\text { Compreender sua } \\
\text { história de vida e } \\
\text { de sua família por } \\
\text { meio de fontes } \\
\text { orais e documentais } \\
\text { (imagens), tendo em } \\
\text { vista suas relações. } \\
\text { Reconhecer que } \\
\text { o espaço vivido é } \\
\text { construído a partir } \\
\text { das relações sociais } \\
\text { e das intervenções } \\
\text { humanas. } \\
\text { Trabalhar o nome } \\
\text { dos locais, função, } \\
\text { características. } \\
\text { Explorar local e } \\
\text { objetos preferidos do } \\
\text { aluno (computador e } \\
\text { XBOX). }\end{array}$ & $\begin{array}{l}\text { Conteúdo } \\
\text { curricular } \\
\text { principal } \\
\text { Geografia } \\
\text { Paisagens: } \\
\text { observação e } \\
\text { preservação de } \\
\text { paisagens de sua } \\
\text { escola e locais } \\
\text { próximos à sua } \\
\text { residência. } \\
\text { Ambiente } \\
\text { familiar, escolar } \\
\text { e circunvizinho. } \\
\text { Espaço da } \\
\text { casa, quarto, } \\
\text { sala, cozinha, } \\
\text { banheiro. } \\
\text { Matemática } \\
\text { Figuras } \\
\text { geométricas. }\end{array}$ \\
\hline
\end{tabular}




\begin{tabular}{|ll|}
\hline Síntese do & A professora Taís apresentou as imagens estimulando o estudante a \\
atendimento & interagir e a se comunicar por meio da seleção de imagens na prancha. \\
& Houve a exploração das imagens com frases do tipo: "De quem é essa \\
& casa?". "Quem mora aqui?". "Onde o Lucas dorme?". "O que tem no \\
& quarto?". "O que tem nessa sala?". "Do que você gosta de brincar?". Lucas \\
& demonstrou maior interesse nesta sessão, reconhecendo o espaço físico \\
& de sua casa e observando os nomes contidos nas pranchas. Manteve-se \\
& atento e repetidamente clicava o mouse sobre as figuras. Sorriu quando \\
& a professora falou do XBOX (videogame), mostrado na tela do notebook, \\
& bastante apreciado pela criança. Antes da professora concluir a atividade, \\
& Lucas levantou-se e dirigiu-se até o outro computador denotando \\
& interesse em jogar (como costumava fazer no AEE). A professora pegou-o \\
& pela mão, retornando à mesa. A professora ofereceu materiais de colagem \\
& para a realização da casinha com figuras geométricas, previamente \\
& recortadas. O estudante não demonstrou interesse em fazer a colagem \\
da casa com figuras geométricas e quis pintar a folha oferecida pela & professora. A professora permitiu que Lucas pintasse a folha, deixando a \\
atividade de montagem da casinha para a próxima sessão.
\end{tabular}

Fonte: registros do diário de campo.

Percebemos que o prosseguimento com uso do software e de outros sistemas de comunicação pode ampliar o vocabulário do estudante. Para isto, é importante conhecer e selecionar os vocábulos emitidos pela criança para identificar e maximizar ações voltadas para ampliar seu repertório comunicacional, conforme explicitam Paura e Deliberato (2014).

Percebemos também que, quando a professora Taís agia com pulso firme e estabelecia pequenas trocas - negociação - com o estudante, comportamentos aparentemente voluntariosos minimizavam-se. Destacamos que durante as sessões percebemos o quanto Lucas apreciava utilizar jogos interativos e diferentes recursos tecnológicos que contêm sons e animações.

\section{Análise e discussão dos resultados}

Como opção para a análise dos dados, adotamos a análise de conteúdo, que tem sido a abordagem apropriada para a análise de materiais volumosos coletados durante o estudo de campo. 
O relato minucioso dos acontecimentos foi feito a partir das observações e registros das intervenções realizadas com o uso de recursos de comunicação aumentativa alternativa, e figuraram em três importantes categorias de análise, a saber: os recursos de CAA na prática pedagógica, as estratégias pedagógicas utilizadas pela professora do AEE para o desenvolvimento das atividades e o desempenho pedagógico do estudante.

A aplicação do Plano de Atendimento Educacional Especializado com o uso do software GRID 2 (PAESG2) favoreceu a eleição de subcategorias: a utilização do GRID 2 como recurso de apoio, o PAESG2 e prática pedagógica na sala de recursos, a interlocução entre as professoras e o processo de registro das reflexões sobre as ações realizadas.

Podemos considerar que o uso do software GRID 2 na sala de recursos pesquisada indicou importantes contribuições desta tecnologia para o desenvolvimento da intencionalidade comunicativa do sujeito estudado: para além das pranchas e das atividades produzidas com o GRID 2, destacamos a forma constante de mediação das professoras, que considerou o estudante em seu aspecto global e em suas especificidades, levando em conta sua bagagem sócio-histórica.

Durante a mediação/intervenção foram observadas intenções comunicativas do estudante. Nesse sentido, redobramos a atenção na observação e significação de cada olhar, apontar, e sorrir do estudante, que foi considerado como um sujeito de inúmeras possibilidades. A espera pelo outro, o apoio e o incentivo à reformulação daquilo que se quer expressar, as modificações e alterações no jogo dialógico são exemplos dessa mediação tendo como referência o uso das pranchas de comunicação.

Dentre as principais dificuldades relatadas pela professora Taís para uso do GRID 2 no AEE, destacamos as dificuldades de confecção das pranchas e da impossibilidade de acesso aos recursos do software (principalmente os recursos de acesso à internet) para dinamizar os atendimentos.

Identificamos alguns fatores que podem ocorrer em todo o Atendimento Educacional Especializado no país: o elevado número de estudantes NEE atendidos no AEE, a necessidade de um tempo maior para planejamento individualizado das ações a serem desenvolvidas nas salas 
de recursos e a necessária articulação do professor do AEE com os professores regentes, assim como a presença dos recursos de tecnologia assistiva sem a devida formação docente para seu uso.

Constatamos a necessidade de os envolvidos no processo educativo se implicarem em ações proativas, com vistas à superação de dificuldades que urgem em ser superadas. Obviamente isso requer reivindicações por melhores condições de trabalho; requer também o envolvimento de toda comunidade escolar com vistas a reivindicar um atendimento educacional de qualidade, que dê conta de responder às demandas educacionais de todos os estudantes.

\section{Considerações finais}

No contexto deste estudo, as dificuldades reveladas nas práxis pedagógicas das professoras de Lucas podem ser facilmente compreendidas quando se reconhece que seus saberes, bem como o de outros profissionais do ensino, histórica e hegemonicamente não têm considerado as diferenças e singularidades nos modos de ensinar e avaliar os estudantes com autismo, o que se revelou, por exemplo, no desconhecimento das profissionais sobre os sistemas de CAA.

A utilização dos recursos de CAA requer, portanto, que o profissional que irá operá-los se aproprie da tecnologia e de métodos específicos para planejar as atividades a serem desenvolvidas, de maneira a atender as necessidades de aprendizagem e de comunicação de um público tão peculiar, como o estudante com autismo, sujeito desse estudo.

Foi constatado que não basta que os sistemas de ensino disponibilizem tecnologias ou recursos de TA nas instituições de ensino se tais ferramentas não satisfazem as necessidades básicas do sujeito e/ou se o seu uso não possui uma intencionalidade pedagógica, comprometida com o conhecimento e com a inclusão dos estudantes NEE.

De forma alguma pretendemos culpabilizar estas profissionais do ensino. Ao contrário, pretendemos elucidar que formas diferentes de 
ensinar e avaliar podem e devem ser facilitadas com o uso de sistemas e recursos específicos para os indivíduos NEE, e que a formação de professores, (tanto a formação inicial quanto a formação continuada e a capacitação profissional) para o conhecimento e uso dos sistemas de CAA na educação desses estudantes é mais que necessária.

As estratégias criadas para viabilizar o potencial comunicativo e de aprendizagem de Lucas, de certa forma, mostraram os desafios vividos pelo estudante no ambiente escolar. Nesse sentido, conhecer outros recursos e métodos para o acesso a conteúdos curriculares possibilitou às professoras compreenderem e assumirem outras práticas, além das tradicionalmente empregadas com o estudante.

No fluxo dessas mudanças, destacamos algumas estratégias utilizadas no processo de intervenção-ação proposto. As contribuições decorrentes do uso da CAA com o estudante residiram primordialmente na relevância desses recursos como dinamizadores dos processos comunicativos do sujeito. Os símbolos representativos daquilo que desejava comunicar possivelmente possibilitaram o início de um processo de fluidez em sua comunicação.

Consideramos relevante também a interlocução observada entre a mãe, a professora do AEE e a professora regente, bem como a interlocução delas com o estudante. Desse modo, podemos afirmar que ao potencializar o uso de recursos de baixa tecnologia e do software GRID 2 , mesmo com os entraves apresentados na licença desta tecnologia para utilização na sala de recursos pesquisada, houve a ampliação e a possibilidade de inserção e participação social do estudante no contexto escolar e domiciliar, privilegiando seu acesso ao conhecimento.

Constatamos que a oferta das licenças para uso do GRID 2, anunciada para oferecer apoio ao trabalho do professor para o atendimento do estudante NEE, pelas dificuldades operacionais apresentadas, resultou em frustração às expectativas dos profissionais das escolas selecionadas com a tecnologia pela não instalação da ferramenta e consequente impossibilidade de acesso e falta de formação para sua aplicação. Dados obtidos nessa pesquisa mostram que foram disponibilizadas pela 
SEDF 70 (setenta) licenças para as escolas, das quais apenas 2 (duas) foram identificadas utilizando o software.

Nesse sentido, registramos aqui a necessidade de maior atenção e compromisso do sistema público de ensino do DF na gestão de estratégias facilitadoras que efetivamente promovam a melhoria da qualidade do ensino, em particular, a intensificação de ações de formação de professores das salas de recursos para o uso intencional e sistematizado de TA voltadas para o atendimento de estudantes NEE. Consideramos também necessárias e urgentes ações efetivas para capacitação de professores das classes comuns para o conhecimento e uso de sistemas de CAA para o atendimento de estudantes com autismo.

Pode-se concluir nesse estudo que os limites e desafios presentes na inserção de TA nas escolas do sistema público de ensino do DF, em particular do software GRID 2, revelam a descontinuidade das ações dos governos, a falta de envolvimento dos professores no processo de inserção dessas ferramentas, a incompatibilidade do sistema operacional possivelmente pela falta de conectividade à internet em algumas escolas —, tendo sido delegada aos educadores a responsabilidade de concretizar a instalação bem como a tarefa de apropriação e conhecimento da ferramenta analisada.

Acreditamos que os registros contidos neste estudo podem contribuir para viabilizar discussões e problematizações sobre os processos de inserção de tecnologias no âmbito escolar e sobre os processos de escolarização de estudantes com autismo. No entanto, as reflexões (e sugestões) aqui trazidas não pretendem ser conclusivas e de forma alguma assumem um papel de completude ou de modelo a ser seguido, mas com certeza se constituirão como exemplo efetivo em possibilidades de atuação profissional consequente no atendimento a estudantes NEE. 


\section{Referências}

BARBIER, R. A pesquisa-ação. Brasília: Plano Editorial, 2002.

BARDIN, L. L'Ére logique. Paris: Robert Laffont, 2011.

BERSCH, R. Design de um serviço de tecnologia assistiva em escolas públicas. 2009. 231 f. Dissertação (Mestrado em Design) - Programa de Pós-Graduação em Design, Faculdade de Arquitetura, Universidade Federal do Rio Grande do Sul, Porto Alegre, 2009.

BRASIL. Ministério da Educação. Secretaria de Educação Especial. Portal de Ajudas Técnicas. Tecnologia Assistiva: recursos de acessibilidade ao computador. Brasília: MEC, 2006. Disponível em: <http://www.educadores.diaadia.pr.gov.br/ arquivos/File/pdf/tecnologia_assistiva.pdf>. Acesso em: 21 nov. 2015.

CORREIA, V. G. P. Alunos com paralisia cerebral na escola: linguagem, comunicação alternativa, e processos comunicativos. 2014. 282 f. Tese (Doutorado em Educação) - Programa de Pós-Graduação em Educação, Universidade Federal do Espírito Santo, 2014.

GALVÃO FILHO, T. A.; DAMASCENO, L. L. Tecnologias Assistivas para Autonomia do Aluno com Necessidades Educacionais Especiais. Revista Inclusão, ano 2, n. 2, p. 25-32, 2006.

PAURA, A. C; DELIBERATO, D. Estudo de vocábulos para avaliação de crianças com deficiência sem linguagem oral. Revista Brasileira de Educação Especial, Marília, v. 20, n. 1, jan./mar. 2014. Disponível em: <http://dx.doi.org/10.1590/ S1413-65382014000100004>. Acesso em: 21 nov. 2014.

SALOMÃO, B. R. O Atendimento Educacional Especializado em uma sala de recursos de Brasília: a sistematização do atendimento e o uso do computador como apoio pedagógico - um estudo de caso. 2013. 152 f. Dissertação (Mestrado em Educação) — Faculdade de Educação, Universidade de Brasília, 2013. 
TECASSISTIVA. 2015. Disponível em: <http://www.tecassistiva.com.br > Acesso em: 15 ago. 2014.

ZAPOROSZENKO, A.; ALENCAR, G. A. R. Comunicação alternativa e paralisia cerebral: recursos didáticos e de expressão. Maringá: UEM, 2008. (Caderno Pedagógico. Série: Educação Especial). Disponível em: <http://www.gestaoescolar.diaadia.pr.gov.br/arquivos/File/producoes_pde/md_ana_zaporoszenko. pdf >. Acesso em: 4 nov. 2014.

WALTER, C. C. F. Efeitos da adaptação do PECS Associada ao Curriculum Funcional Natural das pessoas com Autismo Infantil. 2000. 134 f. Dissertação (Mestrado em Educação Especial) - Programa de Pós-Graduação em Educação Especial, Universidade Federal de São Carlos, 2000.

Recebido: 15/06/2018

Received: 06/15/2018

Aprovado: 10/09/2018 Approved: 09/10/2018 